\title{
Kocabaş Fosil İnsan Kalıntıları Üzerine Yapılan Çalışmaların Değerlendirilmesi
}

\begin{abstract}
Ahmet İhsan Aytek*
Özet

Türkiye coğrafi konumu itibariyle insanların ve memeli hayvanların göç yollarında bulunmaktadır. Kıtalar arası göçlerin aydınlatılmasında Türkiye'de bulunan fosillerin büyük önem taşıması nedeniyle bu coğrafya paleoantropologların büyük ilgisini çekmektedir. 2002 yılında Denizli'nin Kocabaş beldesinde bulunan fosil kafatası parçaları bu göç hareketlerinin aydınlatılması ve arkaik Homo türü gruplarının yerleşmeleri hakkında önemli bir kilometre taşııı. Yakın zamanda yapılan tarihlendirme ile 780 binden yaşlı olduğu belirlenen fosilin yaşı ile morfolojik özelliklerine de bakıldığında Homo sapiens olarak tanımlanamayacağı açık olmakla beraber yapılmış çalışmalar bu fosilin Homo erectus olarak sınıflandırılması gerektiğini göstermektedir. Bu çalışmanın amacı; Kocabaş fosili hakkında yapılan çalışmaları inceleyerek, paleoantropolojik açıdan son derece önemli olan bu fosil ile ilgili olarak genel bir değerlendirme yaparak, aynı zamanda okurlara fosil ile ilgili Türkçe bilgi sunmaktır.
\end{abstract}

Anahtar kelimeler: Kocabaş, kafatası kubbesi, Homo erectus, göç yolları

\footnotetext{
* Araştırma Görevlisi, Mehmet Akif Ersoy Üniversitesi Fen-Edebiyat Fakültesi Antropoloji Bölümü İstiklal Yerleşkesi Burdur. Email: aytek@mehmetakif.edu.tr
} 


\title{
Assessment of the Studies on the Kocabaş Fossil Human Remains
}

\begin{abstract}
Turkey is located one of the possible migration corridors for humans and mammalians. It is a very important region to expose the migration corridors and draws attention of the paleoanthropologists. In 2002 fragments of a skullcap fossil were found in Kocabaş village, Denizli. These find is a milestone to expose the migration corridors and the settlements of early Homo species.

A recent work on the fossils gives a date about $780 \mathrm{KA}$. The morphological features and the age of the fossil clearly indicates that it can't be defined as Homo sapiens. The studies on the specimen attribute the Kocabaş specimen to Homo erectus. The aim of this article is to examine the studies on the Kocabaş specimen and provide a source to Turkish readers.
\end{abstract}

Keywords: Kocabaş, skullcap, Homo erectus, migration corridors

\section{Giriş}

Göçler paleoantropolojinin en önemli konularından biri olup; karasal memelilerin muhtemel göç yolları, bu yolları kullanan türler ve bunların hangi tarihlerde gerçekleştiği uzun zamandır paleoantropologların çalışmalarında önemli bir yer tutmaktadır. Anatomik açıdan modern insanın Afrika dışına çıkışının çok öncesinde, Homo cinsinin diğer bireyleri Afrika’yı terk edip dünyaya yayıldılar. Bu ilkin göçleri kimin, ne zaman gerçekleştirdiği kesin olarak bilinmese de özellikle son 10 yılda Afrika dışında bulunan arkeolojik ve antropolojik kayıtlar bu tarihin sanılandan çok daha eski olduğunu göstermektedir. 2000'li yılların başına kadar Homo cinsinin 500 bin yıl öncesine kadar Afrika dışına çıkmadığı düşünülse de (kısa kronoloji) (Rightmire 1998), yeni buluntular bu düşünceyi çürütüp daha uzun bir kronolojinin varlığını ortaya koymuştur (Gabunia ve ark. 
2000a; Vekua ve ark. 2002). Afrika dışında bulunan en erken insan izlerine baktığımızda; Batı Asya'da (Gürcistan) 1.7 milyon, Avrupa'da 1.2 milyon (İspanya) ve Asya'da (Endonezya) 1.6-1.8 milyon y1l ile tarihlendirilen insan izlerini görmekteyiz (Swisher ve ark. 1994; Gabunia ve ark. 2000a; Carbonell ve ark. 2008). Gürcistan'da bulunan birçok iskelet, tür tanımlaması üzerinde tartışmalar olsa da kesin olarak Homo cinsinin bireyleri olarak tanımlanmış olup; paleomagnetizma, radyometrik tarihlendirme ve biyostratigrafik tarihlendirmelerin hepsinin kesin sonuçlarına dayanarak yapılan tarihlendirmede yaklaşık olarak 1.7 milyon yıl ile tarihlenmiştir (Gabunia ve ark. 2000a, 200b; Vekua ve ark. 2002; Lordkipanidze ve ark. 2006). Endonezya kalıntıları üzerinde tartışmalar olsa da, Gürcistan'da ele geçirilen kalıntılar ve bunlara ait tarihler bize Homo cinsine ait bireylerin kesin olarak 1.7 milyon yıl öncesinde Afrika dışına çıktığını göstermektedir. Bu ilkin göçleri Homo cinsinin diğer türleri devam ettirerek değişik göç yolları üzerinden yeni yerleşim yerlerine doğru dağılımlar gerçekleştirdiler.

Türkiye bulunduğu coğrafi konum itibariyle bu muhtemel göç yollarından biri üzerinde bulunmakta olup, arkeolojik ve antropolojik kayıtların artması ile insanların göç yollarının belirlenmesi açısından önemi her geçen gün artmaktadır. Kitalar arası bir köprü vazifesine sahip olması itibariyle Türkiye hem Homo cinsinin ilk göçlerinin hem de sonraki göç yollarının aydınlatılması açısından çok önemli bir role sahiptir. Türkiye Arkeolojik Yerleşimler Projesinin verilerine göre Türkiye'de 435 Paleolitik ve Epipaleolitik alan vardır (www.tayproject.com). Ancak bunların çoğu araştırılmamıştır.

Buna rağmen alt Paleolitik döneme tarihlendirilen Dursunlu ve Yarımburgaz mağarası; orta Paleolitik döneme tarihlendirilen Karain, Öküzini, Merdivenli ve T1kalı mağaraları ile Beldibi-Kumbucağı ve üst 
Paleolitik buluntuları veren Üçağızlı ve Kanal mağaraları Paleolitik dönem insan yerleşimlerine ait önemli bilgiler sağlamaktadır (Kuhn 2002). Türkiye sadece Paleolitik dönemde değil Miyosen dönemde de önemli bir göç yolu vazifesi görmüştür. Ankarapithecus, Griphopithecus, Ouranopithecus ve Kenyapithecus hominoidlerine ait kalıntılar Türkiye'nin Miyosen dönemde de önemli bir göç yolu olduğunu göstermektedir (Alpagut ve ark. 1990; Alpagut ve ark. 1996; Güleç ve ark. 2007; Kelley ve ark. 2008;).

2002 yılında Pamukkale Üniversitesi öğretim elemanlarından Doç. Dr. M. Cihat Alçiçek tarafından Denizli’nin Kocabaş beldesinde bulunan fosil kalıntısı Homo cinsine ait Türkiye'de bulunmuş en eski kalıntı olmakla beraber, göç yollarının aydınlatılmasında da önemli bir kilometre taşı konumundadir.

\section{Bölgenin Jeoloji ve Kronolojisi}

Denizli'den 26 km uzakta bulunan Kocabaş beldesi, Türkiye'nin en büyük vadi sistemlerinden birisinin içinde yer almaktadır (Şekil 1). Bölge $100 \mathrm{~km}^{2}$ den fazla bir alanı kapsayan Neojen ve Kuaterner dönemlerde oluşmuş yeni ve eski traverten oluşumlarını barındırmaktadır. M.C. Alçiçek'in ifadesine göre fosil bölgede bulunan fabrikalardan birisinin (Dalmersan) traverten sahasından getirilen blokları işlemesi sırasında fabrikada ortaya çıkmış ve işçiler tarafından fark edilmiştir. Daha sonra bölgede jeoloji çalışmaları yürüten M.C. Alçiçek söz konusu işletmeyi ziyareti sırasında bulgunun Homo cinsine ait bir bireye ait olduğunu fark etmiş ve işletme yöneticisinin izni ile incelemek ve kültür varllğ 1 olarak tecil ettirmek üzere almıştır. 
Bölgede kazı alanı olmadığı için fosilin bulunduğu yer yeri fabrika yöneticisi G Vurdaal ile yapılan görüşme ile tespit edilmiştir. Daha sonra fosilin yaşının ne olduğu sorusu gündeme gelmiş ve Kappelman ve ark. (2008) termolüminesans tarihlendirme ile bölgenin 510 ila 390 bin y1l arasında olduğunu belirlemişlerdir, bölgede aynı zamanda Equus, Dama ve Bos cinslerine ait fosiller de bulunmuştur. Ancak adı geçen tarihleme metodunun üst limitinin yaklaşık olarak 500 bin yıl olması fosilin gerçek yaşının belirlenmesinde kesin bilgi vermesini engellemektedir. Daha sonra Türk-Fransız bir ekip tarafından paleomagnetizma ile yapılan yaşlandırma ile fosilin çıktığı seviyenin 780 bin yıldan yaşlı olduğunu (Vialet \& Alçiçek 2012), 2013 yılında yine bir Türk-Fransız ekibi tarafından yapılan nüklid ölçümlere dayalı tarihlendirmede ise seviyenin 1.2 milyon yıldan daha yaşlı olduğu tespit edilmiştir (Vialet ve ark. 2013).

Ayrica aynı alandan fil (Elephas antiquus) ve gergedan (Stephanorhinus $s p$.) kalıntıları da bulunmuş olup bu fosiller ile ilgili çalışmalar Ege Üniversitesi Tabiat Tarihi Uygulama ve Araştırma Merkezi'nde devam etmektedir (Dr. Serdar Mayda ile kişisel görüşme).

\section{Kocabaş Fosili}

Fosil kafatası kubbesi parçalarından oluşmaktadır (Şekil 2). Üç parça halinde olan fosil; sağ parietal parçası, sağ frontal parçası (supraorbital torus ile beraber) ve sol parietal ile frontal kemiğin birleşmesinden oluşan tek bir kemik parçasından oluşmaktadır (Şekil 3). Kafatasının üst kısmı fabrikanın çalışmaları esnasında kesilmiş olup eksiktir.

Mevcut süturlar ve supraorbital torus üzerinde yapılan incelemelere göre kafatası kubbesinin 15-40 yaşları arasında bir erkek bireye ait olduğu düşünülmektedir (Kappelman ve ark., 2008). Supraorbital torusun çok kalın 
olması ve kafatası kubbesinin alçak olması bu fosilin Homo sapiens olarak değerlendirilmesini imkânsız hale getirmektedir. Bu da bize fosilin arkaik bir Homo türü olduğunu gösterir. Ayrıca sağ frontal kemiğin iç kısmında, orbital çukurun hemen altında bir sıra halinde her biri yaklaşık olarak 1-2 mm çapında lezyon oluşumları da göze çarpar (Şekil 4). Fosil halen Denizli Müzeler Müdürlüğüne bağlı Pamukkale Hierapolis Arkeoloji Müzesinde muhafaza edilmektedir.

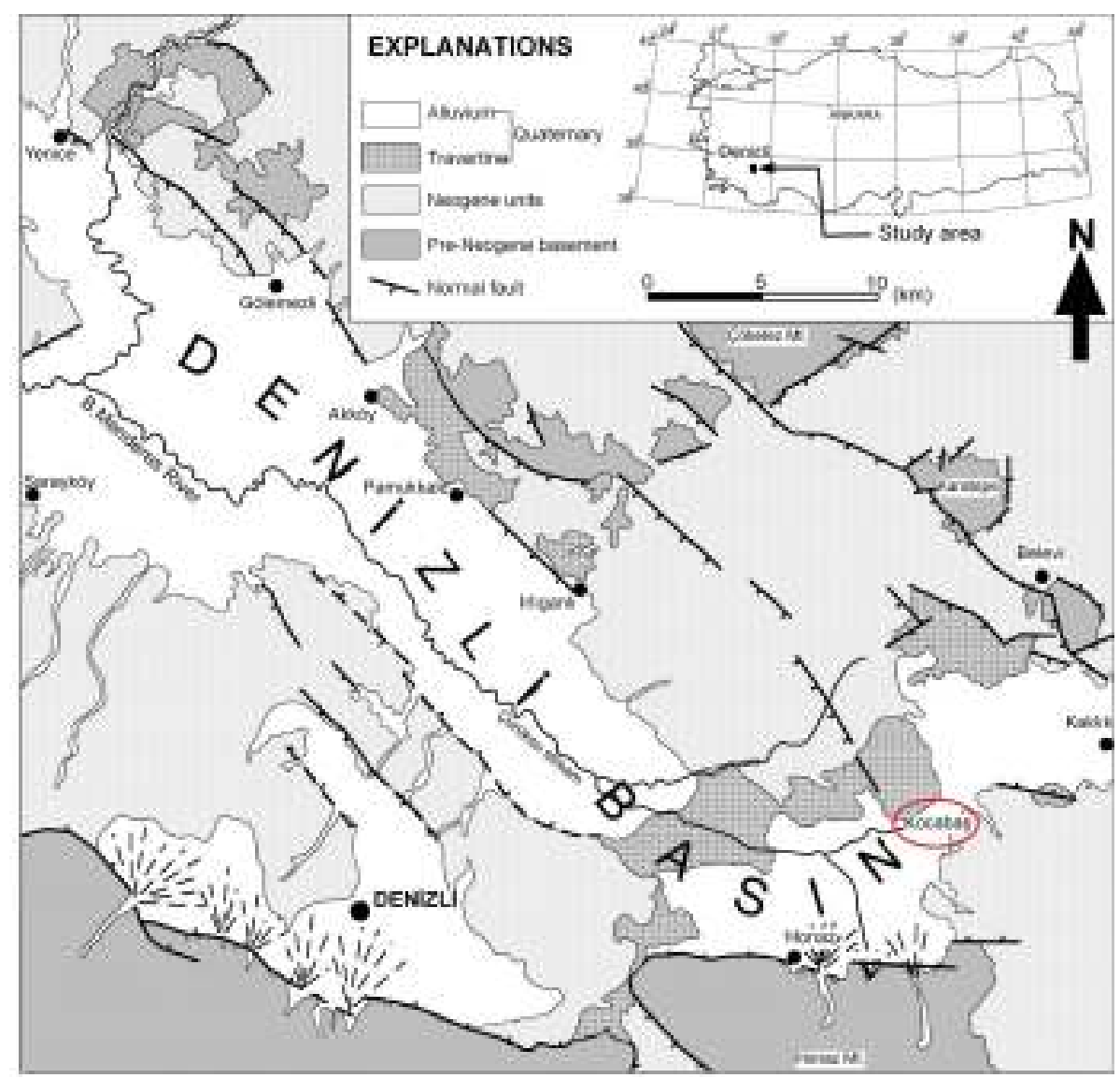

Şekil 1. Kocabaş bölgesinin jeolojik haritası (Özkul ve ark., 2002 den uyarlanmıştır) 


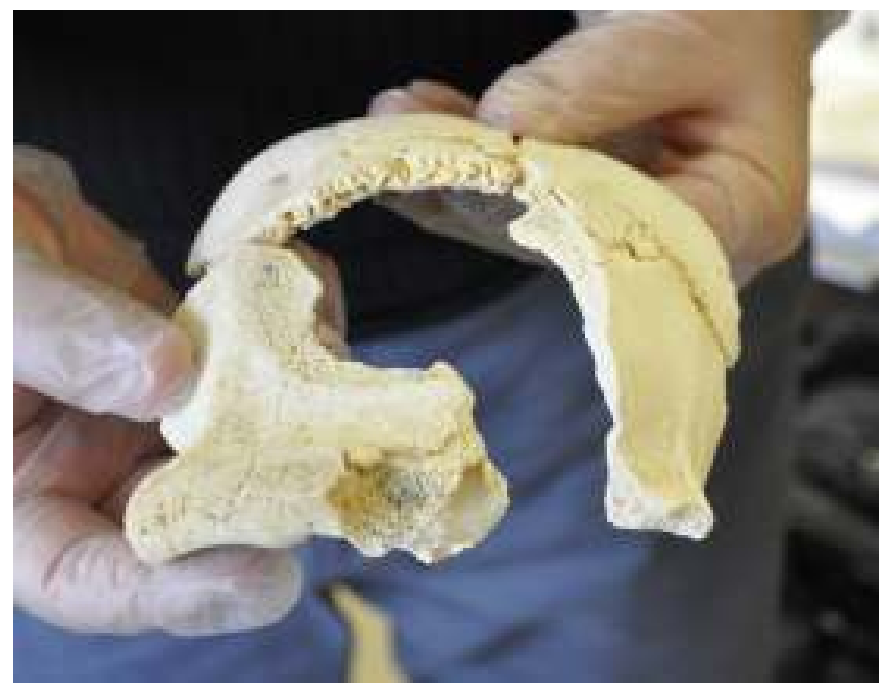

Şekil 2. Fosil kafatası kubbesi.

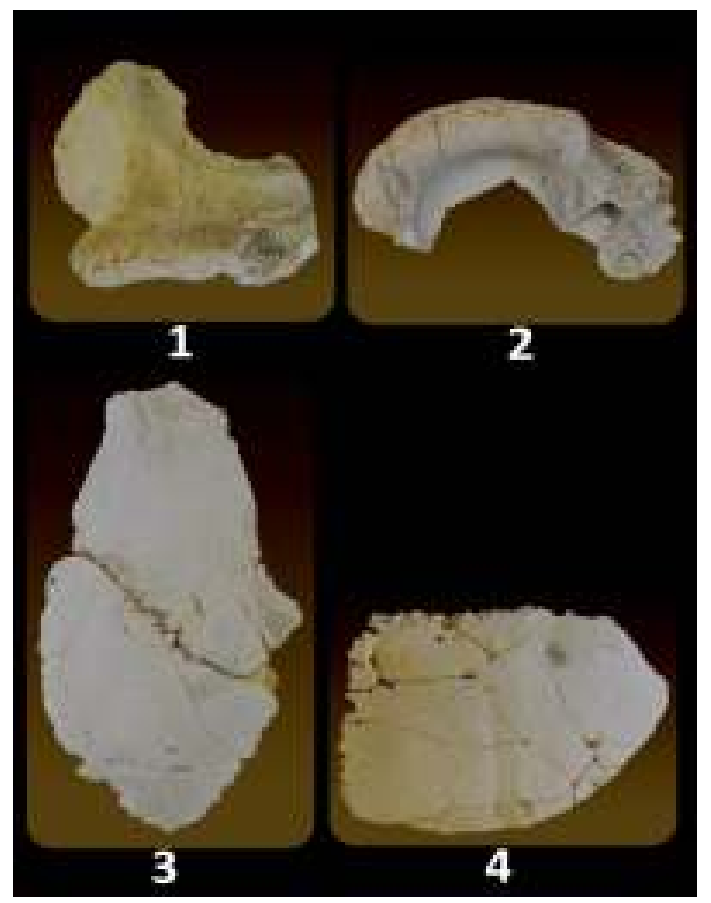

Şekil 3. Kafatası kemikleri; (1) Sağ supraorbital torusun üstten görünüşü, (2) Sağ supraorbital torusun karşıdan görünüşü, (3) Sol frontal ve parietal kemiklerin üstten görünüşü ve (4) Sağ parietal kemiğin üstten görünüşü 


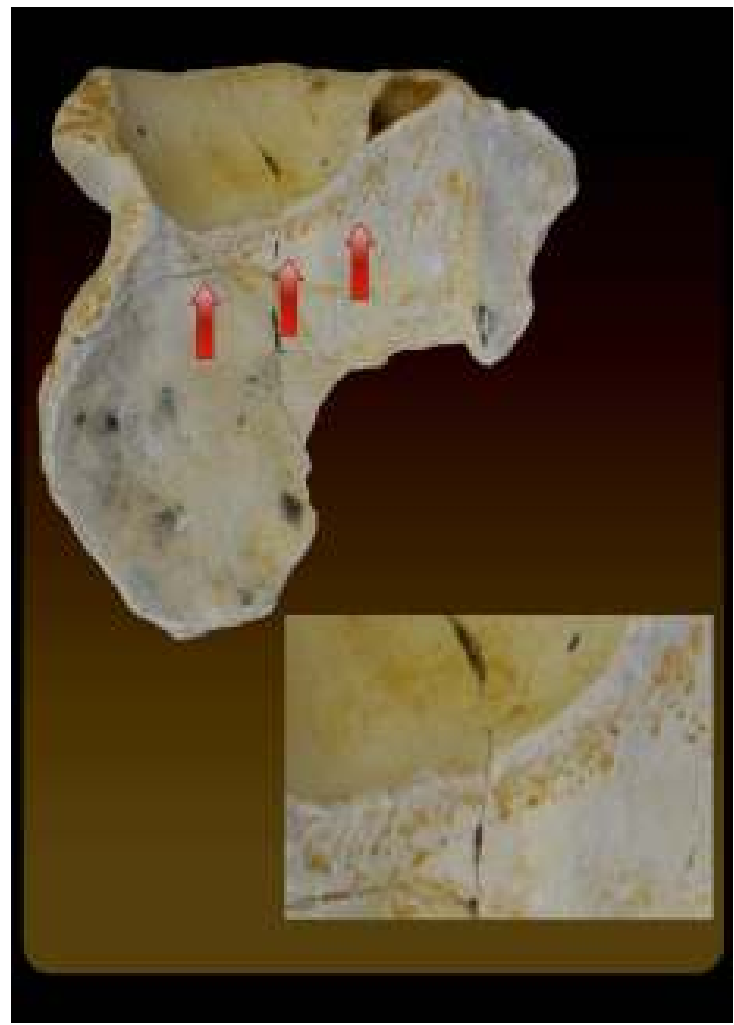

Şekil 4. Frontal kemiğin iç yüzeyindeki lezyonlar.

\section{Fosil Üzerinde Yapılan Çalışmalar}

Fosil üzerindeki ilk çalışma John Kappelman ve arkadaşları tarafından 2008 yılında yayınlanmıştır. Metrik ölçümlere dayalı bu çalışmada mevcut olan sağ supraorbital torus fotoğraf üzerinde kopyalanarak sol supraorbital torus elde edilmiştir ve böylece daha fazla ölçüm alanı elde edilmesi amaçlanmıştır. Çalışmada alınan ölçümler Tablo 1'de verilmektedir. Tablo 1'de görüldüğü üzere değerler tek bir fosil örneğe yakınlık göstermemekle beraber, maksimum biparietal genişliği ve minimum frontal genişliği Asya 
Homo erectuslarına yakınken, supraorbital torus kalınlığı Avrupa ve Afrika Homo heidelbergensislerine yakındır. Maksimum biparietal genişliği, minimum frontal genişliği ile supraorbital torus kalınlıkları üzerinde yapılan çok değişkenli analizler Kocabaş fosilinin Asya Homo erectus bireylerine yakın olduğunu göstermektedir (Sangiran ve Zhoukoudian türleri) (Kappelman ve ark., 2008). Kocabaş fosilinin Homo erectus olarak tanımlanması gerektiği belirtilse de, Kappelman ve ark. (2008) fosilin kesin olarak bir sinıflandırma yapılamayacak durumda olduğunu da belirtmişlerdir.

Çalışmada ayrıca sağ frontal kemiğin iç yüzeyinde görülen lezyonlar da incelenmiştir. Kappelman ve ark., (2008), lezyonların tüberküloz yüzünden oluştuğunu ve bunun bireyin koyu derisinin güneş 1şınından yeteri kadar D vitamini alamadığ için meydana geldiğini belirtmişlerdir. $\mathrm{Bu}$ görüş doğru ise, Kocabaş fosilinin tüberküloz hastalığının bilinen en erken taşıyıcısı olması olasılığı da fosilin önemini arttırmaktadır. Ancak Roberts ve ark. (2009) Kappelman ve arkadaşlarının analiz metotlarını eleştirip, fosil üzerinde D vitamini eksikliğine dair izlerin bulunmadığını, mevcut izlerin tüberküloz tanımı yapmak için yeterli olmadığını ve bu lezyonların araknoid granülasyonlardan (beyin zarlarından birinde meydana gelen çıkıntı) meydana gelen kemik değişimleri olduklarını savunmaktadır.

Fosil üzerinde diğer bir çalışma Amelia Vialet ve arkadaşları tarafından 2012 yılında yayınlanmıştır ve sonuçları Kappelman'ın sonuçlarını destekler niteliktedir. $\mathrm{Bu}$ çalışma da metrik ölçümlere dayalı olmakla birlikte, en büyük farkı metrik ölçümlerin 3 boyutlu görüntü üzerinden alınmasıdır. Fosilin 3 boyutlu görüntüsü 
bilgisayarlı tomografi (CT) ile alındıktan sonra yine sağ supraorbital torus kopyalanarak sol tarafa eklenmiştir (Şekil 5).

Tablo 1. Kappelman ve arkadaşlarının çalışmasında alının ölçümler; italik rakamlar tahmin sonucu elde edilen verilerdir (değerler: mm) (Kappelman ve ark., 2008'den uyarlanmıştır)

\begin{tabular}{|c|c|c|c|c|c|c|c|c|c|}
\hline Asya Fosilleri & Kocabaş & D2280 & D2282 & D2700 & D3444 & $\begin{array}{c}\text { Trinil } \\
2\end{array}$ & San 2 & $\begin{array}{c}\text { San } \\
17\end{array}$ & $\begin{array}{c}\text { Zhou } \\
\mathrm{X}\end{array}$ \\
\hline $\begin{array}{l}\text { Minimum frontal } \\
\text { genișlik (ft-ft) }\end{array}$ & $92 \pm 1$ & 75 & 66 & 67 & 67,5 & 85 & 82 & 95 & 89 \\
\hline $\begin{array}{l}\text { Supraorbital torus } \\
\text { kalınlığg }\end{array}$ & $18 \pm 1$ & 11 & 10,5 & 8 & 10 & 13 & 12 & 17 & 16,5 \\
\hline \multirow[t]{2}{*}{$\begin{array}{l}\text { Maximumbiparietal } \\
\text { genişlik }\end{array}$} & 140 & 119 & 116 & 117 & 122 & 131 & 137 & 142 & 137 \\
\hline & Zhou XI & $\begin{array}{l}\text { Zhou } \\
\text { XII }\end{array}$ & Sam 1 & Sam 3 & Sam 4 & $\mathrm{Ng} 1$ & $\mathrm{Ng} 7$ & $\begin{array}{c}\mathrm{Ng} \\
11 \\
\end{array}$ & Ng 12 \\
\hline $\begin{array}{l}\text { Minimum frontal } \\
\text { genişlik (ft-ft) }\end{array}$ & 84 & 91 & 102 & 101 & 110 & 106 & 103 & 112 & 103 \\
\hline $\begin{array}{l}\text { Supraorbital torus } \\
\text { kalınlığ } 1\end{array}$ & 13,2 & 14,6 & 15 & 13 & 14,5 & 13 & 15 & 12 & 14 \\
\hline $\begin{array}{l}\text { Maximumbiparietal } \\
\text { genişlik }\end{array}$ & 136 & 140 & 146 & 127 & 156 & 149 & 141 & 147 & 139 \\
\hline Afrika Fosilleri & $\begin{array}{c}\text { KNM } \\
\text { ER } 1813\end{array}$ & $\begin{array}{c}\text { KNM } \\
\text { ER } 1470\end{array}$ & $\begin{array}{c}\text { KNM } \\
\text { ER } \\
3733\end{array}$ & $\begin{array}{c}\text { KNM } \\
\text { ER } \\
3883\end{array}$ & $\begin{array}{c}\text { KNM } \\
\text { ER } \\
42700\end{array}$ & $\begin{array}{l}\text { UA } \\
31\end{array}$ & Bouri & $\begin{array}{c}\mathrm{OH} \\
9\end{array}$ & \\
\hline $\begin{array}{l}\text { Minimum frontal } \\
\text { genişlik (ft-ft) }\end{array}$ & 65 & 71 & 83 & 80 & 77 & 78 & $89 \pm 1$ & 88 & \\
\hline $\begin{array}{l}\text { Supraorbital torus } \\
\text { kalınlığ1 }\end{array}$ & 9 & 8 & 8 & 11 & 7 & 15,2 & 18,5 & 19 & \\
\hline \multirow[t]{2}{*}{$\begin{array}{l}\text { Maximumbiparietal } \\
\text { genişlik }\end{array}$} & 100 & 120 & 131 & 134 & 116 & 128 & $\begin{array}{c}133 \pm \\
2 \\
\end{array}$ & 139 & \\
\hline & Bodo & $\begin{array}{c}\text { Broken } \\
\text { Hill }\end{array}$ & & & & & & & \\
\hline $\begin{array}{l}\text { Minimum frontal } \\
\text { genişlik (ft-ft) }\end{array}$ & 105 & 98 & & & & & & & \\
\hline $\begin{array}{l}\text { Supraorbital torus } \\
\text { kalınlığ } 1\end{array}$ & 20 & 23 & & & & & & & \\
\hline $\begin{array}{l}\text { Maximumbiparietal } \\
\text { genişlik }\end{array}$ & 148 & 145 & & & & & & & \\
\hline Avrupa Fosilleri & $\begin{array}{l}\text { Steinhei } \\
\mathrm{m}\end{array}$ & $\begin{array}{c}\text { Petralon } \\
\mathrm{a}\end{array}$ & $\begin{array}{c}\text { Cepran } \\
\mathrm{o}\end{array}$ & & & & & & \\
\hline $\begin{array}{l}\text { Minimum frontal } \\
\text { genișlik (ft-ft) }\end{array}$ & 106 & 110 & 106 & & & & & & \\
\hline $\begin{array}{l}\text { Supraorbital torus } \\
\text { kalınlığ } 1\end{array}$ & 17 & 21 & 21 & & & & & & \\
\hline $\begin{array}{l}\text { Maximumbiparietal } \\
\text { genişlik }\end{array}$ & 137 & 151 & 156 & & & & & & \\
\hline
\end{tabular}


Metrik ölçümler genel olarak aynı olmakla beraber, en belirgin fark supraorbital torusun genişliğinde görülmektedir. $\mathrm{Bu}$ değer, Kappelman'ın çalışmasında 124 mm iken, Vialet'in çalışmasında 116 $\mathrm{mm}$ olarak hesaplanmıştır. Vialet bu farkın kullanılan metotlardan kaynaklandığını söylemektedir (Vialet ve ark., 2012). Bu çalışmada ayrıca kafatasının iç yüzeyinde bulunan damar izleri de incelenmiştir. Vialet ve ark. (2012) post-orbital daralma, belirgin supraorbital torus, beyin atardamarının gelişimi ve pozisyonu ve metrik ölçümlerin benzerliğinden dolayı Kocabaş fosilinin Homo erectus olarak sınıflandırılması gerektiğini belirtmektedirler. Bu çalışma Kocabaş fosilinin morfolojik olarak Zhoukoudian mağarasında bulunan Homo erectus kafataslarına da çok yakın olduğunu göstermektedir.
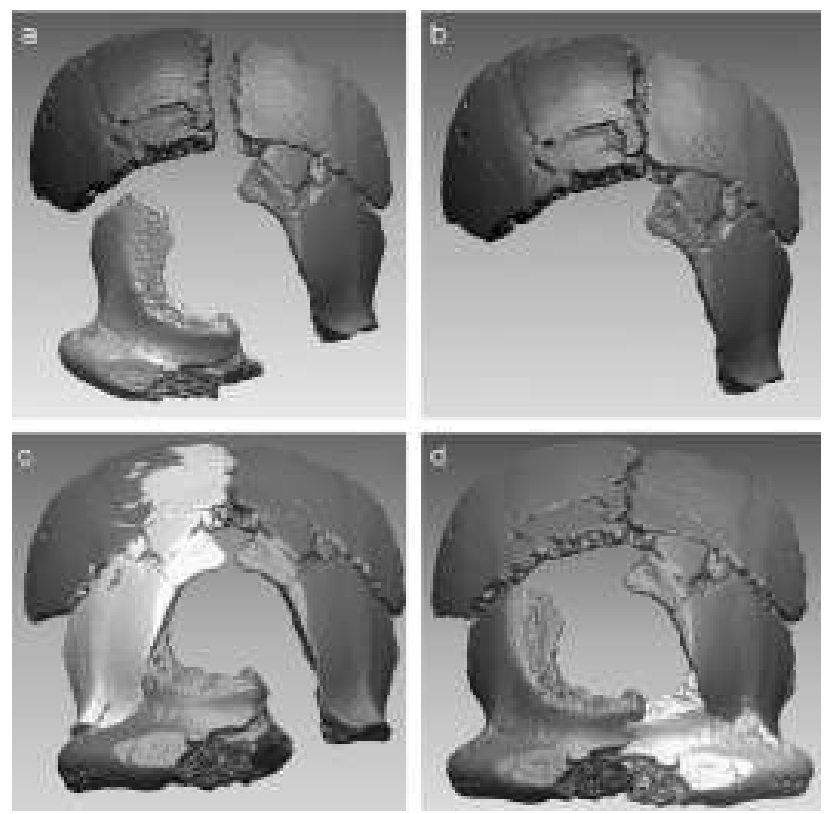

Şekil 5. Vialet ve arkadaşlarının fosilin 3 boyutlu tarama görüntüsü. a,b ve c'de kemiklerin 3 boyutlu görüntülerinin birleştirilmeleri gösterilirken, d'de sağ supraorbital torusdan kopyalanan sol supraorbital torusun kafatasına yerleştirilmesi gösterilmektedir (Vialet ve ark. 2012) 


\section{Sonuç ve Tartışma}

Kocabaş fosilin üzerinde yapılan çalışmalar bu fosilin kesin olarak hangi tür altında sınıflandırılması gerektiğini açıklamasa da fosilin yaşı ve morfolojisi göz önünde alındığında Türkiye'nin en eski insan fosili olduğu şüphesizdir. Sınıflandırma sorunu paleoantropolojide karşılaşılan en büyük sorunlardan biridir ve (muhtemelen en büyüğ̈̈) birçok fosil türün sınıflandırılmasında karşımıza çıkmaktadır. Genel bir örnek olarak Neandertalleri ele aldığımızda; önemli miktarda fosil kalıntısına ve hatta genetik çalışmalara rağmen Neandertallerin ayrı bir tür mü yoksa Homo sapiens 'in bir alt türü mü olduğu tartışması halen devam etmektedir. $\mathrm{Bu}$ noktada Kocabaş fosilinin tek bir parka kalıntıdan oluştuğu, hatta bu parçanın da tam olmadığı düşünüldüğünde net bir bilimsel sınıflandırmanın zorluğu çok açık bir şekilde ortaya çıkmaktadır. Fosilin yaşı ile beraber belirgin supraorbital torus başta olmak üzere mevcut morfolojik özelliklerine baktığımızda bu fosilinin Homo sapiens türü içinde değerlendirilemeyeceği açıktır. Bu da bize Homo sapiens' in Afrika dışına çıkıp yayılım göstermeye başlamasından çok önce Türkiye'nin erken Homo türlerine ev sahipliği yaptığını ve Avrupa'ya doğru kurulmuş göç yollarından biri olabileceğini göstermektedir.

Yapılan iki çalışmada da Kocabaş fosilinin morfolojik özelliklerinin değişik düzeylerde Afrika ve Asya Homo erectuslarına olan benzerlikleri ortaya koyulmuştur. Ayrıca supraorbital torus kalınlığı açısından baktığımızda Homo heidelbergensis'e de yakın 
olduğu görülmektedir. Homo erectus'un Asya ile Afrika grupları arasında büyük bir kafatası morfoloji farkı görülmektedir, 1.5 milyon yıldan daha uzun bir süre yaşayan bir tür olduğunu düşündüğümüzde bu derece bir morfolojik çeşitliliğin gözlenmesi normal kabul edilebilir, hatta bu morfolojik fark, aynı kıtada yaşamış olan Asya grubu bireyleri arasında dahi görülmektedir. $\mathrm{Bu}$ fosil ile ilgili olarak bahsi geçen iki çalışmada da genel olarak fosilin Asya türlerine (Zhoukudian) benzerlikleri belirtilmekle birlikte, metrik ve morfolojik olarak Afrika ve Batı Asya (Dmanisi) fosillerine olan benzerlikler de dikkate alınarak değerlendirilmelidir.

Yine fosilin üzerinde bulunan lezyonların tüberküloz olarak teşhis edilmesi bu hastalığın ilk görülme zamanını çok daha eskiye götürecek olmasından dolayı paleopatoloji araştırmaları için de büyük bir önem taşımaktadır. Fosil üzerinde yapılacak detaylı analizler bu sorunun da cevabının bulunması adına önemlidir. Yukarıda da belirtildiği gibi bölge, Kocabaş fosilinin yanında bir çok memeli fosili barındirmaktadır.

Bu da bize Türkiye'nin sadece insan değil karasal memeli hayvan göçleri için de önemli bir koridor olduğunu gösterir ve bölgenin daha detaylı araştırılması gerekliliğini ortaya koyar.

\section{Kaynakça}

1. Alpagut, B., Andrews, P. ve Martin, L. (1990) 'New hominoid specimens from the Middle Miocene site at Paşalar, Turkey', Journal of Human Evolution 19, $397-422$. 
2. Alpagut, B., Andrews, P., Fortelius, M., Kappelman, J., Temizsoy, İ., Çelebi, H. ve Lindsay, W. (1996) 'A new specimen of Ankarapithecus meteai from the Sinap Formation of Central Anatolia', Nature 382, 349-351.

3. Carbonell, E., Bermúdez de Castro, J.M., Parés J.M., Pérez-González, A., Cuenca-Bescós, G., Ollé, A., Mosquera, M., Huguet, R., van der Made, J., Rosas, A., Sala, R., Vallverdú, J., García, N., Granger, D.E., Martinón-Torres, M., Rodríguez, X.P., Stock, G. M., Vergès, J.M., Allué, E., Burjachs, F., Cáceres, I., Canals, A., Benito, A., Díez, C., Lozano, M., Mateos, A., Navazo, M.,Rodríguez, J., Rosell J. ve Arsuaga J.L. (2008) 'The first hominin of Europe', Nature 452, 465-470.

4. Gabunia, L., Vekua, A., Lordkipanidze, D., Swisher, C.C., Ferring, R., Justus, A., Nioradze, M., Tvalchrelidze, M., Anton, S. C., Bosinski, G., Joris, O, de Lumley, M-A., Majsuradze, G., ve A. Mouskhelishvili. (2000a) 'Earliest Pleistocene cranial remains from Dmanisi, Republic of Georgia: taxonomy, geological setting, and age', Science 288, 1019-1025.

5. Gabunia, L., Vekua, A. ve Lordkipanidze, D. (2000b) 'The environmental contexts of early human occupation og Georgia (Transcaucasia)', Journal of Human Evolution 38, 785-802.

6. Güleç, E., Sevim, A., Pehlevan, C. ve Kaya, F. (2007) 'A new great ape from the late Miocene of Turkey', Anthropological Science 115, 153-158.

7. Kappelman, J., Alçiçek, M.C., Kazanc1, N., Schultz, M., Özkul, M. ve Şen, Ş. (2008) 'Brief communication: First Homo erectus from Turkey and Implications for Migrations into Temperate Eurasia', American Journal of Physical Anthropology 135, 110-116.

8. Kelley, J, Andrews, P. ve Alpagut, B. (2007) 'A new hominoid species from the middle Miocene site of Paşalar, Turkey', Journal of Human Evolution 54, 455-479.

9. Kuhn, S. L. (2002) 'Paleolithic archaeology in Turkey', Evolutionary Anthropology 11, 198-210. 
10. Lordkipanidze, D., Vekua, A., Ferring, R., Rightmire, G.P., Zollikofer, C.P.E., Ponce De Léon, M.S., Agusti, J., Kiladze, G., Mouskhelishvili, A., Nioradze M. ve Tappen, M. (2006) 'A Fourth Hominin Skull From Dmanisi, Georgia', The Anatomical Record Part A 288A, 1146-1157.

11. Özkul, M., Varol, B. ve Alçiçek, M.C. (2002) 'Depositional Environments Aan Petrography Of Denizli Travertine', Mineral Research Exploration Bulletin 125,13-29.

12. Roberts, C.A., Pfister, L. ve Mays, S. (2009) 'Letter to the Editor: Was Tuberculosis Present in Homo erectus in Turkey?', American Journal of Physical Anthropology 139, 442-444.

13. Rightmire, G.P. (1998) 'Human Evolution in the Middle Pleistocene: The Role of Homo heidelbergensis', Evolutionary Anthropology 6 (6), 218-227.

14. Swisher, C.C. III., Curtis, G.H., Jacob, T., Getty, A.G., Suprijo, A., ve Widiasmoro. (1994) 'Age of earliest known hominids in Java, Indonesia', Science 263, 1118-1121.

15. Vekua, A., Lordkipanidze, D., Rightmire, G.P., Agusti, J., Ferring, R., Maisuradze, G., Mouskhelishvili, A., Niorada, M., Ponce de Leon, M., Tappen, M., Tvalchrelidze, M. ve Zoolikofer, C. (2002) 'A new skull of early Homo from Dmanisi, Georgia', Science 297, 85-89.

16. Vialet, A., Guipert, G. ve Alçiçek, M.C. (2012) 'Homo erectus found still further west: Reconstruction of the Kocabas, cranium (Denizli, Turkey)', Comptes Rendus Paleovol 11 (2-3), 89-95.

17. Vialet, A. ve Alçiçek, M.C. (2012) 'A Lower Pleistocene human fossil from Kocabaş (Denizli, Turkey) pushing Homo erectus far to the west of Asia', 2. Annual Meeting of the European Society for the study of Human Evolution, Eylül 2012, Fransa.

18. Vialet, A., Lebatard, A-E, Alçiçek, M.C., Rochette, P., Khatib, S., Boulbes, N., Bourles, D., Guipert, G. ve Mayda, S. (2013) 'The Homo erectus from Turkey. New results from the anthropological study of the Kocabaş reconstructed skull and the chronological framework on the Denizli Basin', 3. Annual Meeting of the European Society for the study of Human Evolution, Eylül 2013, Avusturya. 
